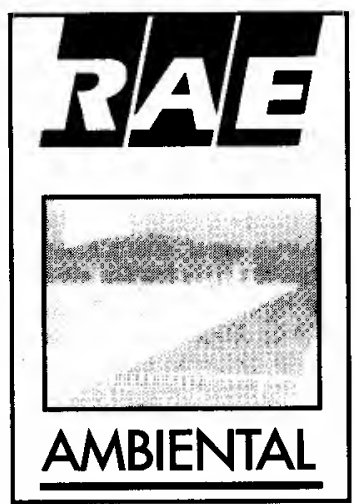

\title{
ISO 14000 - A NOVA NORMA DE GERENCIAMENTOE CERTIFICAÇÃO AMBIENTAL
}

A futura norma internacional para o meio ambiente - a série ISO 14000 - e a importância para as empresas de certificação de seus sistemas de gerenciamento ambiental.

The future international environment standard - the ISO 14000 series - and the importance of the environmental management systems certification for the enterprises.

\section{PALAVRAS-CHAVE:}

ISO 14000, BS7750, sistemas de gerenciamento ambiental. normas internacionais, certificação ambiental.

\section{KEY WORDS:}

ISO 14000 , BS 7750 , environmental management systems. international standards, environmental certification.
*Diretor-Executivo do QSP Centro Brasileiro da Qualidade, Seguranca $\theta$ Produtividade $\theta$ do Clube da 1509000.

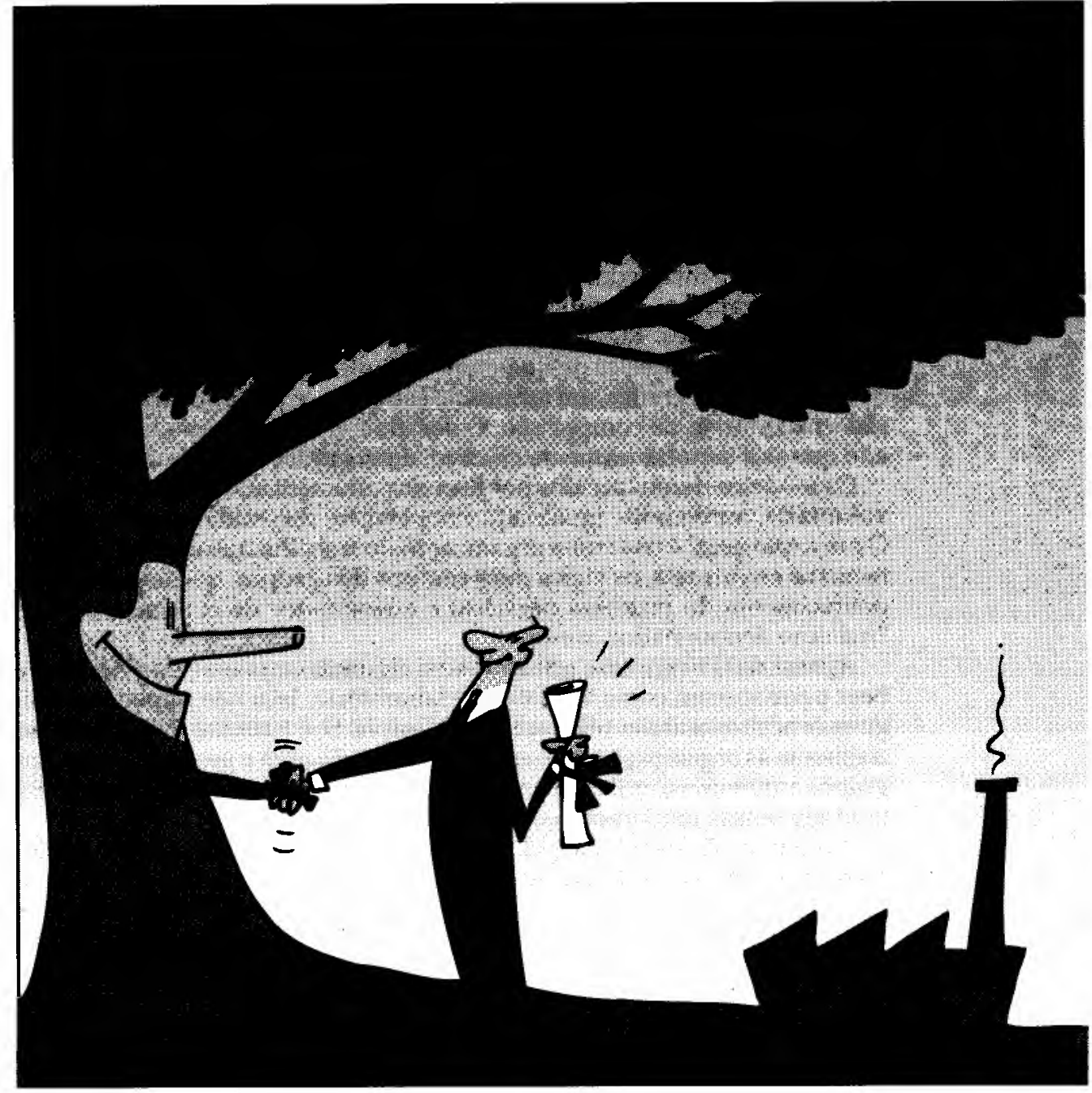

São Paulo, v. 34, n. 5, p. 80-84 
No ano retrasado, a BSI - British Standards Institution - publicou uma nova norma "revolucionária" de gerenciamento: a BS 7750, uma norma para o controle ambiental, tanto na indústria como no setor de serviços.

A BSI também foi a primeira na área da qualidade, com a norma BS 5750 que serviu de modelo para a ISO 9000 . O pioneirismo da BSI está se repetindo novamente com a nova norma ambiental.

Dois acontecimentos estão confirmando o surgimento, entre 1995 e 1996, de uma. norma internacional sobre gerenciamento ambiental: a nova regulamentação da União Européia - UE, e os trabalhos em ritmo acelerado para a versão ISO da norma britânica - a série ISO 14000.

A Europa foi a pioneira na utilização da ISO 9000, ao adotá-la como padrão de gerenciamento da qualidade, por ocasião da unificação européia. Atualmente, uma nova regulamentação deverá surgir, exigindo, para sua implementação, um sistema de gerenciamento ambiental apoiado numa norma aceitável por todos. A única norma com essas características, até a série ISO 14000 ser editada, é a BS 7750.

O título da regulamentação européia é Sistema de Eco-Gerenciamento e Auditoria, já conhecida como Eco-Auditoria. Ela é facultativa, nesses próximos três anos, para a indústria e o setor de serviços, mas já é obrigatória para o governo dos doze países-membro que deverão constituir organizações nacionais para sua administração e certificação.
Uma explicação simples para a importância da relação entre a norma e a regulamentaçấo européia é que, se uma empresa implementar a BS 7750, ela automaticamente estará qualificada para obter a certificação, de acordo com os requisitos da Eco-Auditoria.

Essa nova norma é revolucionária porque permite às empresas garantir e comprovar, através da chancela de um organismo certificador independente, tanto seu gerenciamento da qualidade como seu gerenciamento ambiental. Em função disso, é muito provável que na Europa, num futuro próximo, as ações judiciais "verdes" não fundamentadas deixem de existir. E as indústrias, pela primeira vez, poderão demonstrar que são ecologicamente corretas e utilizar sua certificação ambiental como um agressivo elemento de marketing.

As empresas certificadas pela ISO 9000 levam uma vantagem significativa sobre as demais, uma vez que grande parte dos requisitos da nova norma ambiental se ajusta perfeitamente aos requisitos da ISO 9000. Um enfoque que deverá ser cada ve $z$ mais considcrado é a implementação dessas duas normas como um sistema integrado, especialmente naquelas organizações que devem demonstrar que têm uma atuação ambiental responsável.

A BS 7750 engloba também as questões de uso e de segurança de produtos, sendo um ótimo mecanismo para incorporar as exigências relativas à segurança e à saúde dos trabalhadores.

É importante destacar que as normas

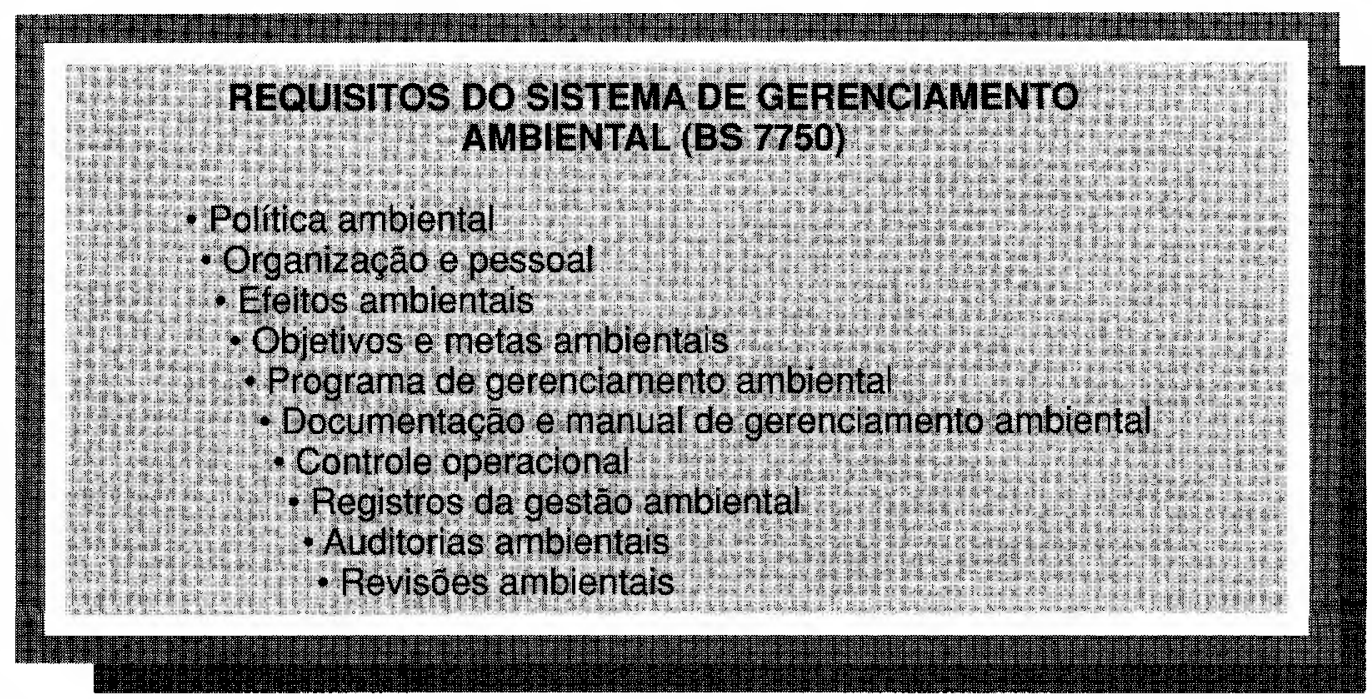

C 1994, Revista de Administração de Empresas / EAESP / FGV, São Paulo, Brasil. 
Executivos da indústria de embalagem acreditam que as questões ambientais são, provavelmente, o maior desafio que estão tendo que enfrentar nesta década. As metas da legislação alemã, que prevê que as indústrias locais devem coletar e reciclar, até o final de 1995, nada menos que $80 \%$ dos resíduos de embalagem, estão sendo vistas como quase impossíveis de serem atingidas.

citadas permitem às empresas em geral estabelecer seu próprio critério de desempenho, tanto em relação à qualidade como em relação à proteção do meio ambiente.

Existe, entretanto, uma diferença básica entre as duas normas. Para uma melhor compreensão dessa diferença, vamos considerar o exemplo a seguir.

Imagine que existam duas especificações para dois tipos diferentes de vidro: um para ser utilizado nos caixilhos de uma edificação e outro para ser utilizado em óculos de segurança, que deve resistir a impactos para não ferir seu usuário.

A qualidade do segundo, ou sua conformidade com os requisitos, não ć menor que a do primeiro, e cada um deles poderá atender à ISO 9000 se seus sistemas do gerenciamento garantirem atendimento contínuo a suas respectivas especificações.

A norma ambiental, todavia, não é assim tão liberal. Existem leis e regulamentos que, em certos casos, não permitem nenhum tipo de poluição da água ou do ar. Apesar de a faculdade que a norma ambiental dá à empresa de definir seus próprios critérios de desempenho, ela tem menos liberdade em relação à sua produção do que em relação à ISO 9000.

Suponhamos agora que uma fábrica de copos de cristal adote a ISO 9000 como padrão para seu sistema de gestão da qualidade. A certificação dessa empresa pela ISO 9000 assegura ao cliente que os belos produtos de cristal, que são fornecidos para suas lojas em diversas partes do mundo, continuarão a sê-lo com a mesma qualidade especificada, e estarão também em ordem os procedimentos de controle dessa qualidade e seus mecanismos de gestão.

Atendendo também à BS 7750, o fabricante de copos de cristal poderá continuar a fornecê-los em todo o mundo como produtos de qualidade assegurada e com a garantia de que seus fornos não poluam a atmosfera nem contaminem a água e de que seus resíduos não scjam tóxicos.

Em resumo, a ISO 9000 estabclece todos os procedimentos necessários para manter a qualidade dos produtos e a inte-

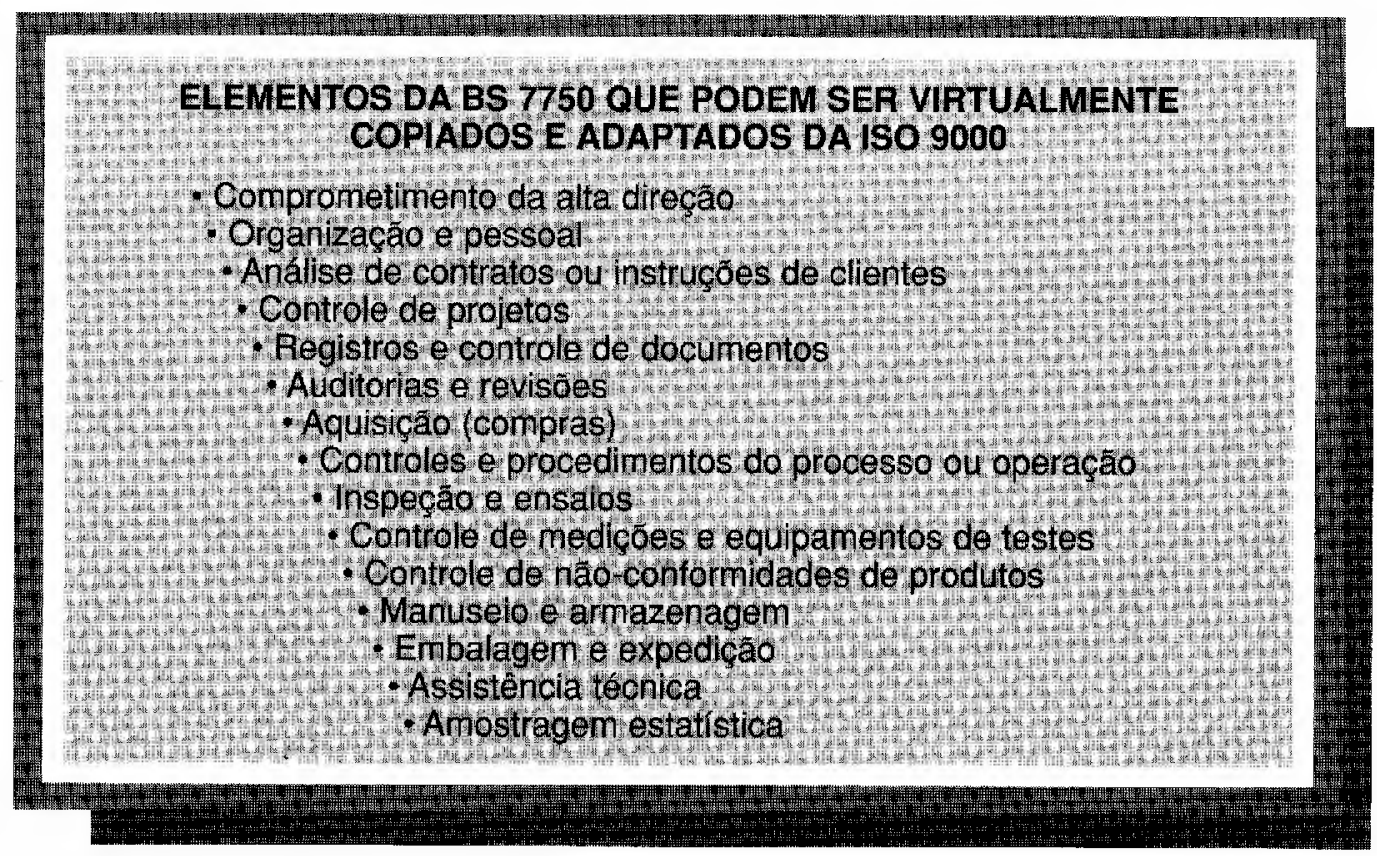


gridade dos processos que levam a essa qualidade. A BS 7750, por sua vez, estabelece os procedimentos que asseguram que a qualidade alcançada e seus respectivos processos não provocam danos ambientais. A ISO 9000 trata dos processos que dão suporte à qualidade; a BS 7750 trata dos processos que dão suporte à eliminação/redução dos riscos ao meio ambiente. Diversos métodos e formas de controle são comuns a ambas as normas.

\section{PEFLEXOS PARA O SETOR DE EMBRALGEUS}

Uma das áreas mais afetadas pela legislação ambiental européia é o setor de embalagens, o que inclui as indústrias, os distribuidores, os revendedores e os próprios consumidores.

$\mathrm{O}$ aspecto que mais preocupa esse setor é a nova diretiva da Uniäo Européia, específica sobre o tema, que deverá entrar brevemente em vigor.

O objetivo dessa legislação é reduzir o impacto global dos resíduos de embalagem no meio ambiente, através de medidas como: diminuição da quantidade de materiais utilizados, incentivo à recuperação e reciclagem. das embalagens e minimização do volume de resíduos que vão para os aterros. A meta é fazer com que, em dez anos após a diretiva da UE tornar-se lei, sejam removidos $90 \%$ do peso dos resíduos de embalagem a serem recuperados.

A. Alemanha não esperou por essa diretiva e desde $1^{\circ}$ de janeiro de 1993, qualquer tipo de embalagem deve ser produzido com materiais "ambientalmente toleráveis", utilizando-se quantidades mínimas de embalagem nos produtos. Para o assombro de muitos exportadores, indústrias e revendedores estão sendo obrigados a transportar de volta para seus países de origem as embalagens näo-conformes dos produtos exportados para a Alemanha.

Executivos da indústria de embalagem acreditam que as questões ambientais são, provavelmente, o maior desafio que estão tendo que enfrentar nesta década. As metas da legislação alemã, que prevê que as indústrias locais devam coletar e reciclar, até o final de 1995 , nada menos que $80 \%$ dos resíduos de embalagem, estão sendo vistas como quase impossíveis de serem atingidas.

A diretiva da UE sobre embalagem será, portanto, um pouco mais moderada...

\section{A SÉRIE ISO TAUOD E SUA IMPORTÃNCIA PARA O BRASIL}

Procuramos mostrar, ao longo deste artigo, que um dos mais importantes fatores determinantes da competitividade de uma empresa no mercado internacional é, e será cada vez mais, a qualidade dos seus sistemas de gerenciamento ambiental, através dos quais são estabelecidos os procedimentos a serem seguidos com vistas a atender aos dispositivos legais e normativos.

A exemplo do que fez com a série ISO 9000, a International Organization for Standardization - ISO está formulando as normas que estabelecerão as diretrizes para se avaliar, universalmente, a qualidade e a eficácia das relações entre as empresas e o meio ambiente.

Tais normas, em elaboração pelo Comitê Técnico 207, instalado em março de 1993, começarão a ser publicadas já no próximo ano, designadas como série ISO 14000 , e seu potencial de impacto, sobre a competitividade de um país, uma região ou um setor produtivo, precisa ser constante e detidamente avaliado.

A defesa do meio ambiente pode abrigar protecionismos, especialmente os que se destinam a manter atividades produtivas que, por fatores econômicos ou operacionais, não conseguem concorrer em regime de liberdade comercial.

Para que o Brasil, através da Associação Brasileira de Normas Técnicas $A B N T$, seja adequadamente representado no TC-207 da ISO, especialmente nos vá- 


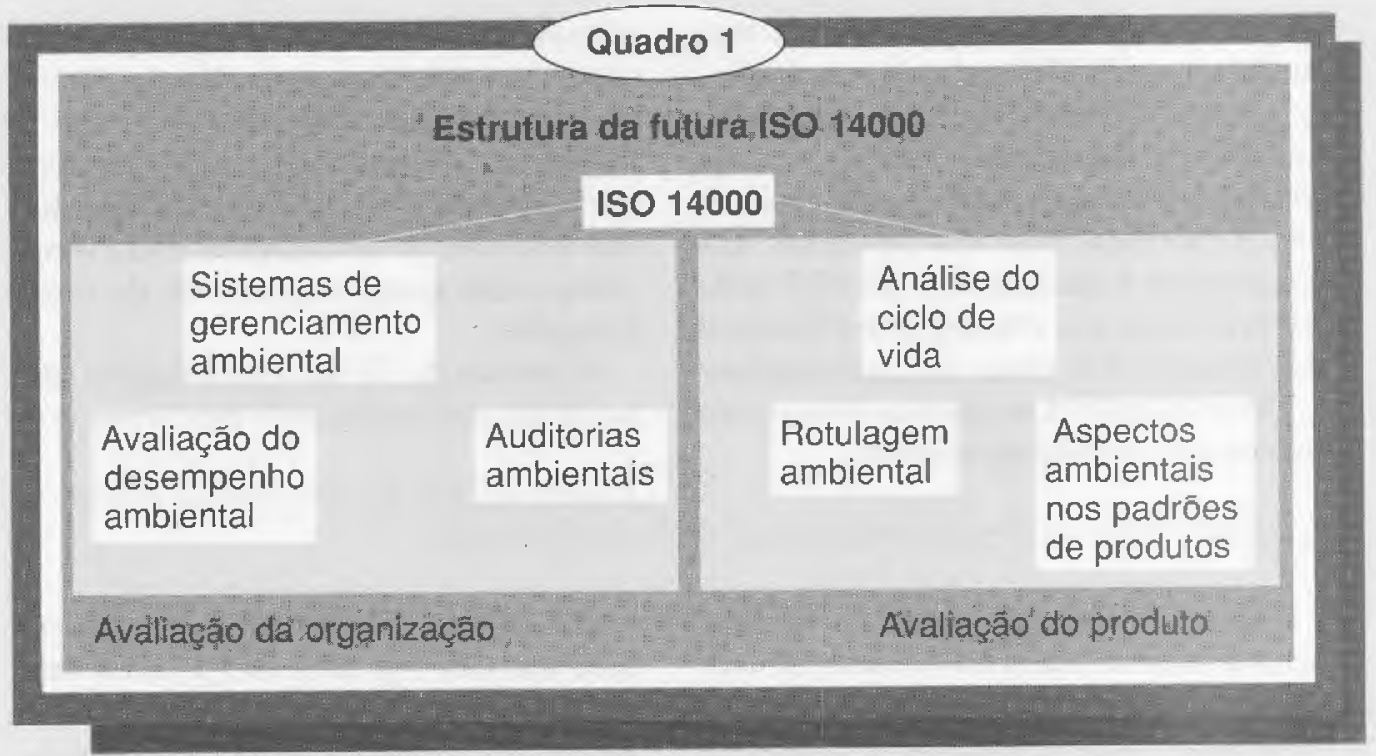

rios subcomitês e grupos que o compõem, a comunidade empresarial brasileira está se mobilizando para proceder à análise das normas já propostas, à avaliaçăo do impacto que podem trazer sobre a atividade econômica nacional e à formulação de proposições alternativas que atendam aos legítimos interesses nacionais.

A série ISO 14000 abrangerá seis áreas: sistemas de gerenciamento ambiental, auditorias ambientais, avaliação do desempenho ambiental, rotulagem ambiental, análise do ciclo de vida e aspectos ambientais relacionados a produtos. $O$ quadro 1 ilustra a estrutura da futura ISO 14000 (ver quadro 1).

A melhoria da imagem das empresas que demonstrarem adequação à ISO 14000 perante a comunidade e o público em geral, e a melhoria dos produtos finais rela- tivamente aos impactos ambientais por eles provocados, são benefícios evidentes que já podem ser antevistos. Indiscutivelmente, o maior apelo para as empresas deverá ser o de natureza comercial.

Embora de uso facultativo na maior parte dos casos, a ISO 9000 tornou-se o passaporte para os mercados internacionais, organizados em blocos cada vez mais coesos sob a ótica das leis e normas adotadas por seus membros. Espera-se que a certificação dọ sistemas de gerenciamento ambiental segundo a ISO 14000 tomese, rapidamente, um fator diferenciador de competitividade das empresas, verdadeiro "salvo-conduto" para o comércio internacional.

\section{8}

\section{BIBLIOGRAFIA SUPLEMENTAR}

- BRITISH STANDARDS INSTITUTION. Specification for environmental management systems. BS 7750: 1992. London.

- NATIONAL ISO 9000 SUPPORT GROUP. The environmental management standard. Continuous improvement. Alto, MI, p. 1-3, Sep. /1993.

- REIS, Maurício J. L. Certificação ambiental: um fator de risco para a competitividade nacional. In: 1 SEMINÁRIO SOBREA ISO 14000, São Paulo, 1994. Anais. São Paulo, QSP/Núcleo ISO 14000. 